\title{
Corrigendum to "A Rare Anatomical Variation of the Termination of Right and Left Cephalic Veins"
}

\author{
Raymond Saa-Eru Maalman $\left(\mathbb{D},{ }^{1}\right.$ Yaw Otchere Donkor $\left(\mathbb{D},{ }^{1}\right.$ \\ Ali M. Ayamba, ${ }^{1}$ and Jubilant Kwame Abledu $\mathbb{1}^{2}{ }^{2}$ \\ ${ }^{1}$ Department of Basic Medical Sciences, School of Medicine, University of Health and Allied Sciences, Ho, Volta Region, Ghana
}

${ }^{2}$ School of Veterinary Medicine, University of Ghana, Legon, Accra, Ghana

Correspondence should be addressed to Raymond Saa-Eru Maalman; rmaalman@uhas.edu.gh

Received 1 April 2018; Accepted 4 April 2018; Published 14 May 2018

Copyright (c) 2018 Raymond Saa-Eru Maalman et al. This is an open access article distributed under the Creative Commons Attribution License, which permits unrestricted use, distribution, and reproduction in any medium, provided the original work is properly cited.

In the article titled "A Rare Anatomical Variation of the Termination of Right and Left Cephalic Veins" [1], there were errors in the Abstract and the Introduction section.

In the Abstract, the text reading "In this report, we describe a case of an anomalous cephalic vein with a bifid course of terminations on both left and right upper limbs which has not been described by previous literature" should be corrected as "In this report, we describe a case of an anomalous cephalic vein with a bifid course of terminations on both left and right upper limbs which has not been described by the previous literature."

In addition, the text reading "During routine gross anatomy dissection of the neck, we observed a rare case of variation of the termination of the cephalic vein in both right and left upper limbs, of a male cadaver" should be removed.

In the Introduction section, the text reading "In this report, we describe a case of an anomalous cephalic vein with a bifid course of terminations on both left and right upper limbs which has not been described by the previous literature" should be removed.

In addition, the text reading "The cut-down of cephalic vein in the deltopectoral groove is preferred when superior vena caval infusion is necessary" should be removed.

Finally, the text reading "Despite the clinical importance of the cephalic vein, anatomical variations in its course and diameter of the cephalic vein may limit or complicate insertion of one or several leads" should be corrected as "Despite the clinical importance of the cephalic vein, anatomical variations in its course and diameter may limit or complicate insertion of one or several leads."

\section{References}

[1] R. S. Maalman, Y. O. Donkor, A. M. Ayamba, and J. K. Abledu, "A rare anatomical variation of the termination of right and left cephalic veins," Case Reports in Vascular Medicine, vol. 2018, Article ID 5809656, 3 pages, 2018. 


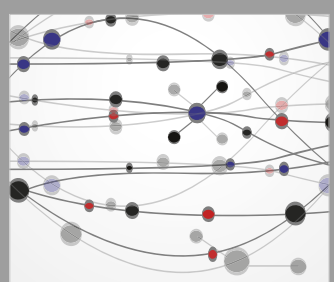

The Scientific World Journal
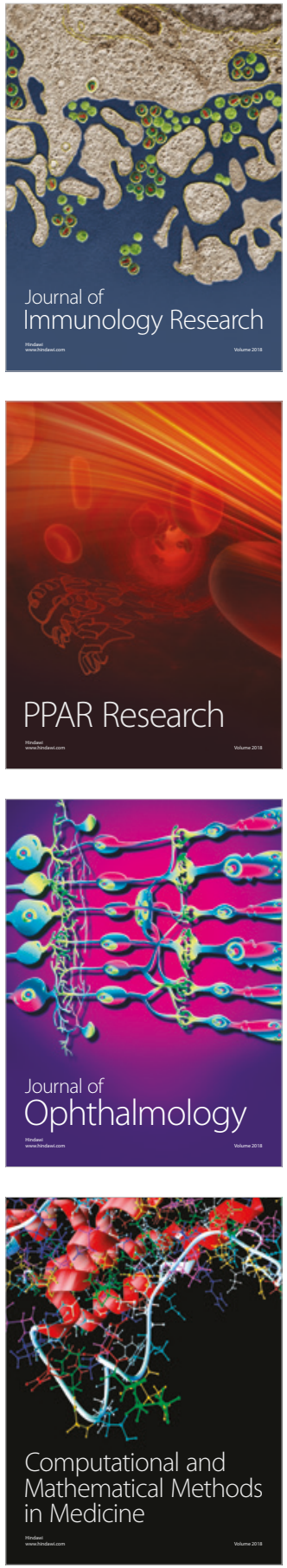

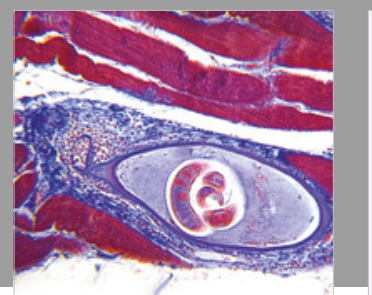

Gastroenterology Research and Practice

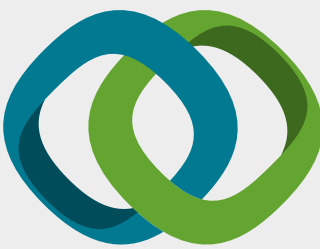

\section{Hindawi}

Submit your manuscripts at

www.hindawi.com
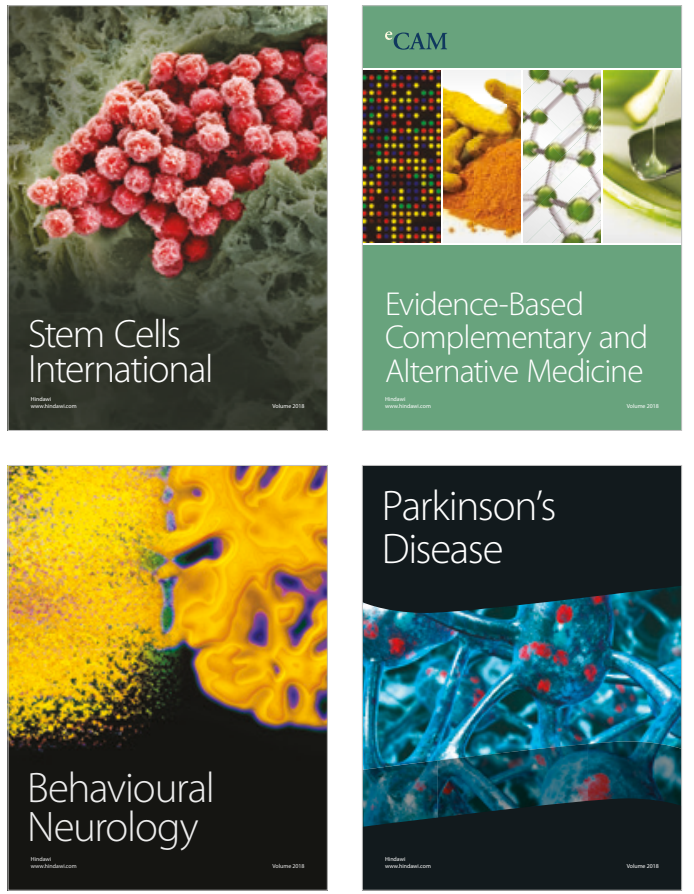

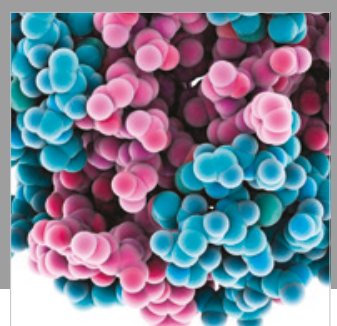

ournal of

Diabetes Research

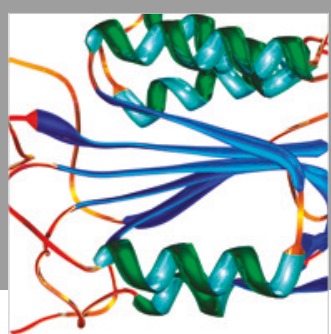

Disease Markers
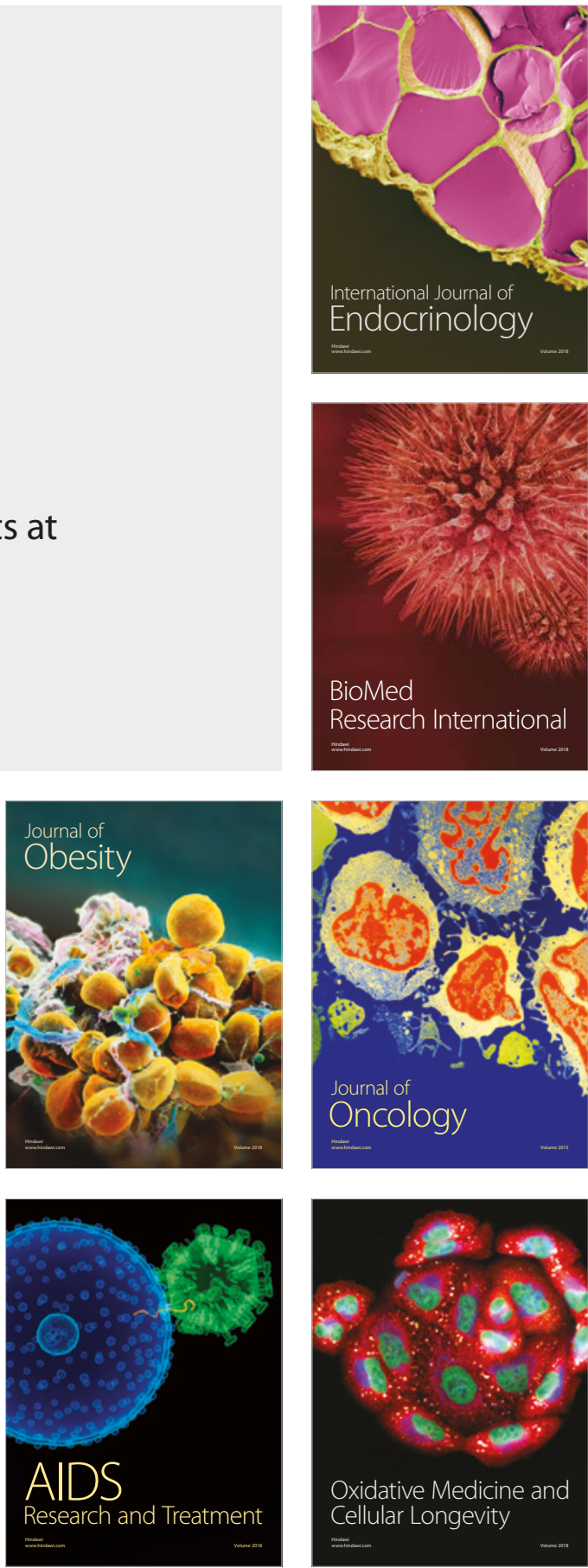